\title{
Synthesis and Characterization of Ferroelectric Liquid Crystalline Organosiloxanes Containing 4-(4-undecanyloxy bi-phenyl-1-carboxyloxy)phenyl (2S,3S)-2-chloro-3- methylvalerate and 4-(4-undecanyloxybenzoyloxy)biphenyl (2S,3S)-2-chloro-3-methylvalerate
}

\section{Chih-Hung Lin ${ }^{1,2, *}$}

1 Center for General Education, Chang Gung University of Science and Technology, No.261, Wenhua 1st Rd., Guishan Township, Taoyuan County 33303, Taiwan

2 Research Center for Industry of Human Ecology, Chang Gung University of Science and Technology, No.261, Wenhua 1st Rd., Guishan Township, Taoyuan County 33303, Taiwan

* Author to whom correspondence should be addressed; E-Mail: chlin@ gw.cgust.edu.tw. Tel.: +886-3-2118999 (ext. 5621); Fax: +886-3-2118866.

Received: 16 August 2013; in revised form: 29 September 2013 / Accepted: 30 September 2013 / Published: 25 October 2013

\begin{abstract}
A series of new organosiloxane ferroelectric liquid crystalline (FLC) materials have been synthesized, and their mesomorphic and physical properties have been characterized. Four new disiloxanes and trisiloxanes, containing biphenyl 4-hydroxybenzoate and phenyl 4-hydroxybiphenylcarboxylate as mesogenic units and eleven methylene unit as spacers and $(2 S, 3 S)$-2-chloro-3-methylvalerate unit as chiral end groups. The molecule, using three phenyl ring as a mesogenic unit, formulates much wider liquid crystalline phase temperature ranges than that of a two phenyl ring unit. The phenyl arrangement differences of mesogenic unit result in the greater differences of the liquid crystal phase formation. The siloxane molecule induction is helpful to the more regular smectic phase formation and smectic phase stabilization, such as chiral $S_{C}\left(S_{C}{ }^{*}\right)$ and $S_{B}$ phases. The siloxane molecule is helpful to reduce the phase transition temperature and broaden the liquid crystal temperature range of the $\mathrm{S}_{\mathrm{C}} *$ phase and, simultaneously, it will not induce chain crystallization phenomenon and dilute the $P$ s value. The synthesis and characterization of the new FLCs materials, which exhibit a room temperature $\mathrm{S}_{\mathrm{C}}$ * phase and higher spontaneous polarization are presented.
\end{abstract}


Keywords: siloxane; spontaneous polarization; ferroelectric liquid crystal

\section{Introduction}

Organosiloxane low molar mass (LMM) liquid crystals have attracted considerable interest because their electro-optic properties are similar to those of classical LMM liquid crystals, demonstrating fast switching times in the nematic [1], $\mathrm{S}_{\mathrm{A}}$ [2], and $\mathrm{S}_{\mathrm{C}} *$ phases [3-5]. Ferroelectric liquid crystalline (FLC) materials, exhibiting a room temperature $S_{C} *$ phase and low melting temperatures are of great interest to researchers in the electro-optic field [6-11]. They are the basis of a variety of potential devices, ranging from large-area flat-panel displays, ultrafast electro-optic modulators, and spatial light modulators [12-16].

FLC molecules consist of a rigid core and end-tail groups with a chiral center located on one or both groups. The mesogenic moiety usually uses a benzene ring as rigid core, and the number of the benzene ring will influence the temperature range of the liquid crystal. For most FLC molecules, the end-tail groups are hydrocarbon chains. When increasing the hydrocarbon chain lengths of the molecules, the rotational viscosity, as well as the tilt angle of the $\mathrm{S}_{\mathrm{C}}{ }^{*}$ molecules, increase. Increasing the length of the non-polar moiety helps to dilute the transverse dipole moment in the material and thus decrease the value of $P s$, whereas, the increase of the tilt angle should have a tendency to increase $P s$ and the FLC molecule is also easier to crystallize.

Recently, we have synthesized a series of organosiloxane FLC materials with a biphenyl mesogenic moiety [17]. In this study, we designed and prepared two new series of molecules, which contains two chiral centers and dimethylsiloxyl (or trimethylsiloxyl) substituent groups linked through flexible hydrocarbon chains. The difference between these two series is the sequence of the phenyl rings' arrangements in the rigid core structure. The substitution of methylsiloxyl groups was expected to enhance the thermal stability and $P s$ value of the FLC materials [18-21].

\section{Results and Discussion}

This study intends to explore two influences: one is the influence of the liquid crystal compound with siloxane end-tail, and the other is the influence from different rigid core arrangements in the mesogenic unit that change the thermal properties of liquid crystalline and liquid crystal mesophase.

In order to clarify the influences, two series of liquid crystal compounds with different mesogenic moieties have been designed and synthesized (series UBPV and series UPBV). Schemes 1,2 illustrate the synthesis procedure of the reaction intermediates and the liquid crystal compounds, and all the products of these two series were examined by the nuclear magnetic resonance spectrometer to verify the correction of the molecular structure. 
Scheme 1. Synthesis of compounds UBPV, d-Si-UBPV, and t-Si-UBPV. (series UBPV) * chiral center.

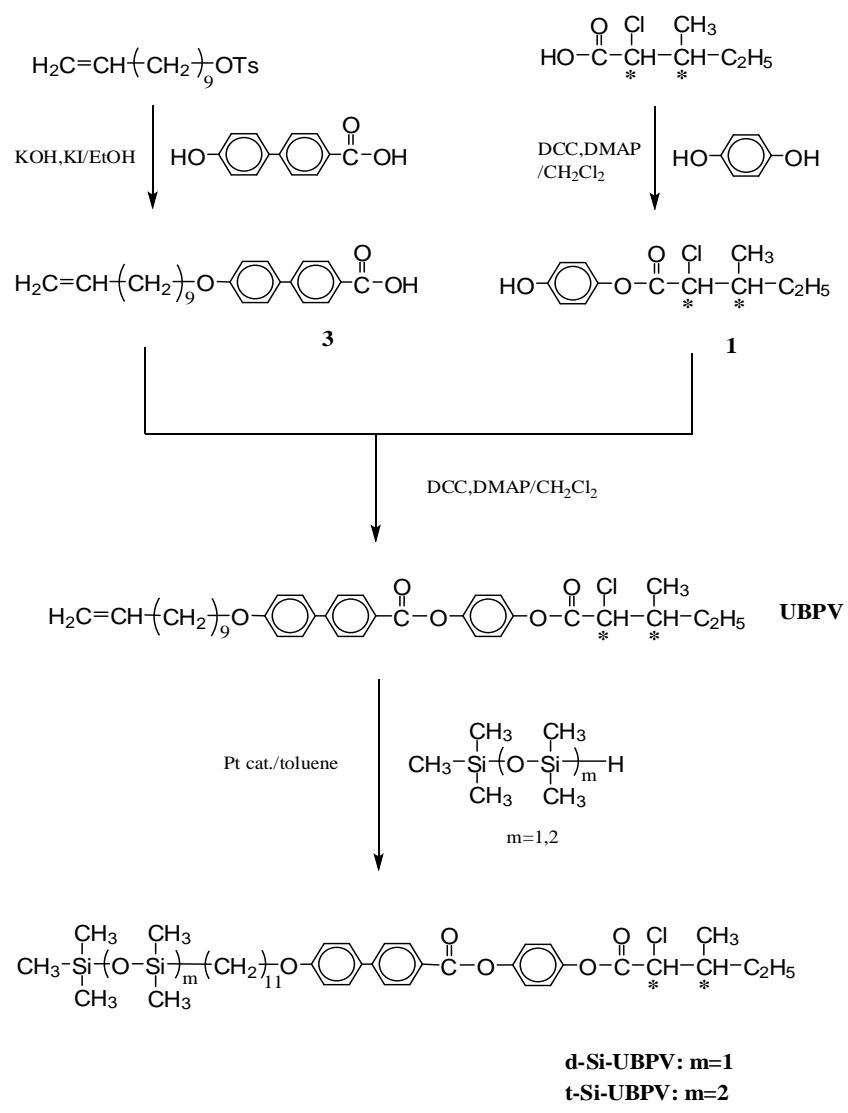

Scheme 2. Synthesis of compounds UPBV, d-Si-UPBV, and t-Si-UPBV. * chiral center.

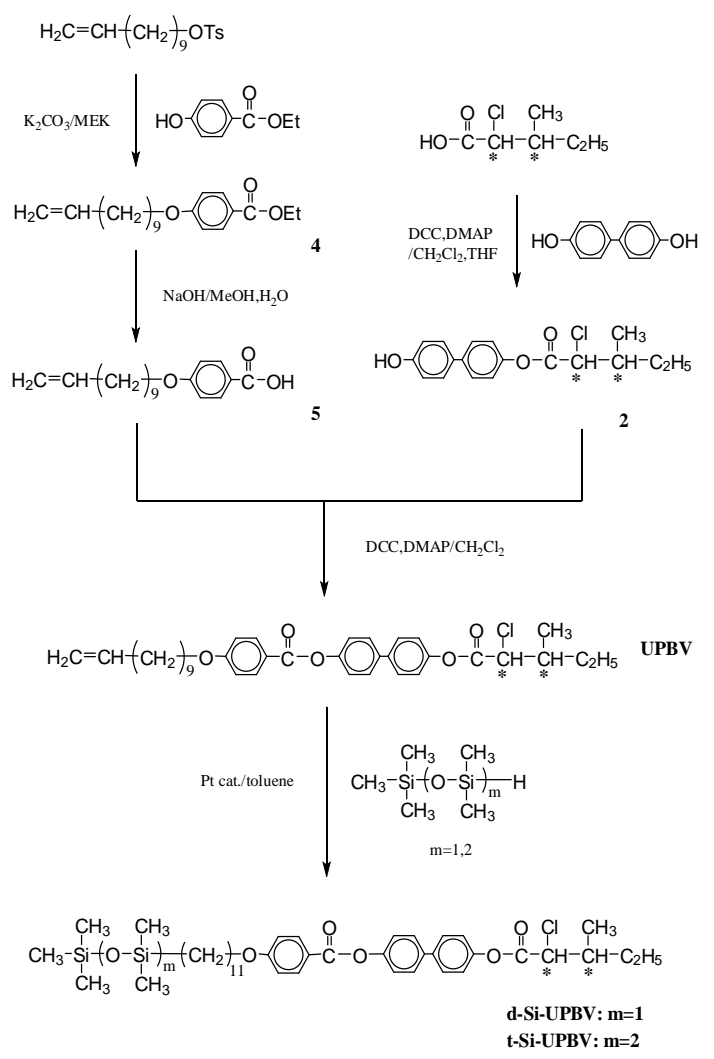


In the UBPV series of compounds (UBPV, d-Si-UBPV, and t-Si-UBPV), a biphenyl group accompanying a phenyl group are used as the mesogenic units; but in the UPBV series of compounds (UPBV, d-Si-UPBV, and t-Si-UPBV) different phenyl rings arrangement in order are applied to explore the influence of different rigid core in the liquid crystal compounds. In addition, three different end-tails, which are ethylene, dimethylsiloxyl, and trimethylsiloxyl groups, were incorporated to the core through an eleven-carbon aliphatic spacer in each series.

The thermal and mesomorphic properties of compounds series UBPV and series UPBV were measured using differential scanning calorimeter(DSC) and polarized optical microscope(POM). The phase transition temperatures and enthalpy change of series UBPV compounds are listed in Table 1. As the mesogenic units in the series UBPV compounds, containing three phenyl rings, the biphenyl segment is linked directly to the spacer, but is farther from the chiral group. Surprisingly, this series compounds do not possess a $\mathrm{S}_{\mathrm{C}}{ }^{*}$ phase. In the cooling process, compound UBPV owns an enantiotropic $S_{A}$ phase in which the temperature range is about $37{ }^{\circ} \mathrm{C}$ and a monotropic $S_{B}$ phase in which the temperature range is about $10^{\circ} \mathrm{C}$. When siloxane was inducted into UBPV, d-Si-UBPV, and $\mathrm{t}$-Si-UBPV were obtained; they showed an enantiotropic $\mathrm{S}_{\mathrm{B}}$ phase with a quite larger temperature range of about $100{ }^{\circ} \mathrm{C}$. In addition, the $S_{A}$ phase is diminished and almost overlaps with other liquid crystal mesophases. The DSC analysis diagram of compound d-Si-UBPV is depicted in Figure 1. Compound d-Si-UBPV, equipped with a liquid crystalline texture diagram of $S_{A}$ and $S_{B}$ by using POM is shown in Figure 2A,C. Figure $2 \mathrm{~B}$ depicts the liquid crystalline texture diagram of phase transition process from the $S_{A}$ phase to the $S_{B}$ phase.

Figure 1. DSC thermograms of compound d-Si-UBPV $\left(10^{\circ} \mathrm{C} / \mathrm{min}\right)$ for $(\mathbf{A})$ second heating scanning and (B) cooling scanning. $\mathrm{K}=$ crystal; $\mathrm{S}_{\mathrm{A}}=$ smectic $\mathrm{A} ; \mathrm{S}_{\mathrm{B}}=$ smectic $\mathrm{B}$.

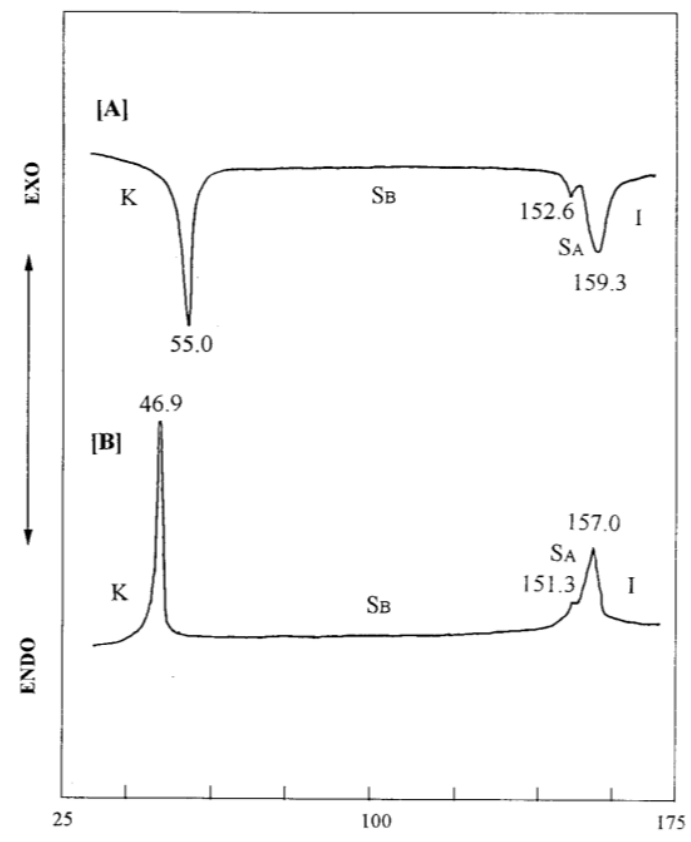


Figure 2. Polarizing optical micrographs (magnification $\times 320$ ) of compound d-Si-UBPV in (A) $\mathrm{S}_{\mathrm{A}}$ texture obtained after cooling from isotropic phase to $155{ }^{\circ} \mathrm{C}$ and (B) $\mathrm{S}_{\mathrm{A}}$ to $\mathrm{S}_{\mathrm{B}}$ texture obtained after cooling to $151{ }^{\circ} \mathrm{C} ;(\mathbf{C}) \mathrm{S}_{\mathrm{B}}$ texture obtained after cooling to $140{ }^{\circ} \mathrm{C}$.

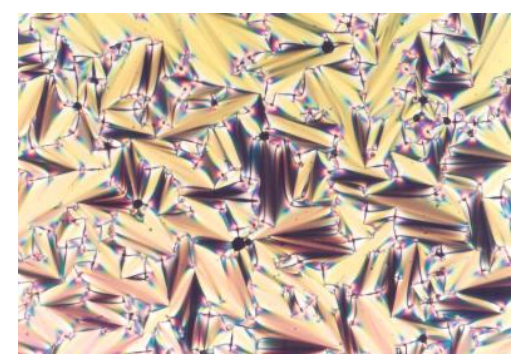

(A)

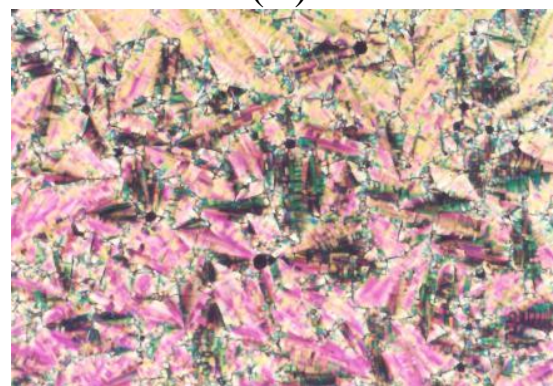

(B)

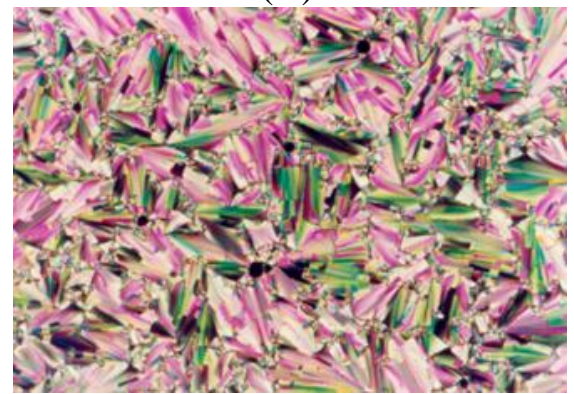

(C)

Table 1. Thermal transitions of compounds UBPV, d-Si-UBPV and t-Si-UBPV.

\begin{tabular}{cc}
\hline \multirow{2}{*}{ Compound } & $\begin{array}{c}\text { Phase transitions, }{ }^{\circ} \mathbf{C} \text { (corresponding enthalpy changes, } \\
\text { Kcal/mole) }\end{array}$ \\
\cline { 2 - 2 } UBPV & $\frac{\text { heating }}{\text { cooling }}$ \\
\hline d-Si-UBPV & $\frac{K 55.8(3.21) S_{\mathrm{A}} 105(-)^{\mathrm{a}} I}{I 97.0(-) S_{\mathrm{A}} 60.1(-0.14) S_{B} 50.8(-2.49) K}$ \\
t-Si-UBPV & $\frac{K 55.0(2.27) S_{\mathrm{B}} 153(0.07) S_{\mathrm{A}} 159(1.16) \mathrm{I}}{I 157(-1.21) S_{\mathrm{A}} 151(-0.07) S_{\mathrm{B}} 46.9(-1.95) K}$ \\
& $K 40.2(1.84) S_{\mathrm{B}} 143(0.14) S_{\mathrm{A}} 150(0.68) \mathrm{I}$ \\
\hline & $I 147(-0.50) S_{\mathrm{A}} 141(-0.10) S_{\mathrm{B}} 33.3(-1.51) K$ \\
\hline
\end{tabular}

$\mathrm{K}=$ crystal; $\mathrm{S}_{\mathrm{A}}=$ smectic $\mathrm{A} ; \mathrm{S}_{\mathrm{B}}=$ smectic $\mathrm{B} ;$ I=isotropic. ${ }^{\text {a }}$ determined by optical polarizing microscopic observation.

Among the UBPV series compounds, t-Si-UBPV has the widest liquid crystalline temperature range $\left(113.7{ }^{\circ} \mathrm{C}\right.$ ), and the liquid crystalline temperature range of compound d-Si-UBPV is slightly lower. 
The compound UBPV shows the smallest liquid crystalline temperature range of $46.2{ }^{\circ} \mathrm{C}$. Consequently, the results can verify a fact that siloxane group is able to stabilize the liquid crystalline formation and the more regular smectic formation, such as the $S_{A}$ phase changing to the $S_{B}$ phase.

The phase transition temperatures and enthalpy change of compounds UPBVs are listed in Table 2. The phase transition of compound UPBV displays both enantiotropic chiral nematic and $\mathrm{S}_{\mathrm{A}}$ phase. When siloxane was inducted into compound UPBV, the results of compound d-Si-UPBV and $\mathrm{t}$-Si-UPBV were obtained, possessing a liquid crystalline phase with the temperature range of about $152{ }^{\circ} \mathrm{C}$. Furthermore, two situations appear: one is an enantiotropic $\mathrm{S}_{\mathrm{C}}$ * liquid crystal phase with the temperature range of about $100{ }^{\circ} \mathrm{C}$. The other is a more regulated smectic phase, either an $\mathrm{S}_{\mathrm{F}}$ liquid crystal phase or an $S_{I}$ liquid crystal phase, with a cooling function to lower the transition temperatures of the above $\left(\mathrm{S}_{\mathrm{F}}\right.$ or $\left.\mathrm{S}_{\mathrm{I}}\right)$ liquid crystal phases. Thus, compound UPBV shows a phase transition temperature at $43.4^{\circ} \mathrm{C}$ and compounds d-Si-UPBV and t-Si-UPBV show phase transition temperatures at $-11.9{ }^{\circ} \mathrm{C}$ and $-15.4{ }^{\circ} \mathrm{C}$, respectively. Figure 3 depicts the DSC analysis diagram of compound d-Si-UPBV. As a result, it can be summarized that the flexible siloxane molecule induction is helpful in lowering the liquid crystalline phase transition temperature and stabilizing the smectic phase formation, such as chiral nematic phase changing to the $\mathrm{S}_{\mathrm{C}} *$ phase.

Table 2. Thermal transitions of compounds UPBV, d-Si-UPBV and t-Si-UPBV.

\begin{tabular}{cc}
\hline \multirow{2}{*}{ Compound } & $\begin{array}{c}\text { Phase transitions, }{ }^{\circ} \mathbf{C} \text { (corresponding enthalpy changes, } \\
\text { Kcal/mole) }\end{array}$ \\
\cline { 2 - 2 } & $\frac{K \text { heating }}{\text { cooling }}$ \\
\hline UPBV & $\frac{K 44.2(2.03) S_{\mathrm{A}} 118(0.07) N^{*} 129(0.13) \mathrm{I}}{I 126(-0.17) N^{*} 114(-0.03) S_{\mathrm{A}} 43.4(-0.88) K}$ \\
d-Si-UPBV & $\frac{K 12.6(1.05) S_{X} 44.0(0.37) S_{C}{ }^{*} 144(2.14) \mathrm{I}}{I 140(-1.98) S_{C}{ }^{*} 40.1(-0.26) S_{X}-11.9(-0.63) K}$ \\
t-Si-UPBV & $\frac{K 9.4(1.29) S_{X} 42.7(0.08) S_{C}{ }^{*} 142(2.40) \mathrm{I}}{I 139(-1.95) S_{C}{ }^{*} 38.4(-0.12) S_{X}-15.4(-0.56) K}$ \\
\hline
\end{tabular}

$\mathrm{K}=$ crystal; $S_{C}{ }^{*}=$ chiral smectic C; $S_{X}=$ smectic phase; $\mathrm{N}^{*}=$ chiral nematic phase; I=isotropic.

Figure 3. DSC thermograms of compound d-Si-UPBV $\left(10^{\circ} \mathrm{C} / \mathrm{min}\right)$ for $(\mathbf{A})$ second heating scanning and (B) cooling scanning. $\mathrm{K}=$ crystal; $S_{C}{ }^{*}=$ chiral smectic $\mathrm{C}$; $S_{X}=$ smectic phase.

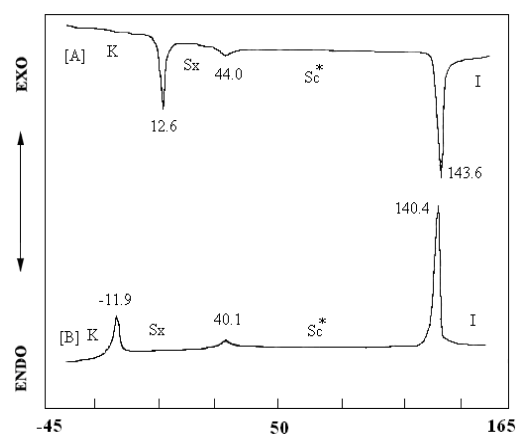


The formation of a $\mathrm{S}_{\mathrm{C}} *$ phase was further verified by spontaneous polarization $(P S)$ measurements. Compounds d-Si-UPBV and t-Si-UPBV were filled into a four-milligram thick cell, made of ITO glass, of which the surface was coated in polyimide, which was rubbed in a parallel direction. Voltage (about $5 \mathrm{~V} / \mu \mathrm{m}$ ) of $50 \mathrm{~Hz}$ frequency and $20 \mathrm{Vp}$ (peak voltage) was used, and the measurement area was $0.26 \mathrm{~cm}^{2}$. The sample was heated to an isotropic temperature, adding voltage to sample in the cooling process. Measurements of $P s$ value and rotational viscosity were taken every $0.5-1{ }^{\circ} \mathrm{C}$ during the $\mathrm{S}_{\mathrm{C}} *$ mesophase range.

The $P s$ value and rotational viscosity of various compounds have the tendency to drop when the temperatures increases. Figure 4 represents the spontaneous polarization $(P s)$ as a function of temperature for compound d-Si-UPBV. The maximum $P s$ value of compound d-Si-UPBV was about $200 \mathrm{nC} / \mathrm{cm}^{2}$ at $50{ }^{\circ} \mathrm{C}$, compound t-Si-UPBV was about $197 \mathrm{nC} / \mathrm{cm}^{2}$ at $44{ }^{\circ} \mathrm{C}$.

Figure 4. Spontaneous polarization $(P s)$ and viscosity vs. temperature for compound (A) d-Si-UPBV and (B) t-Si-UPBV.

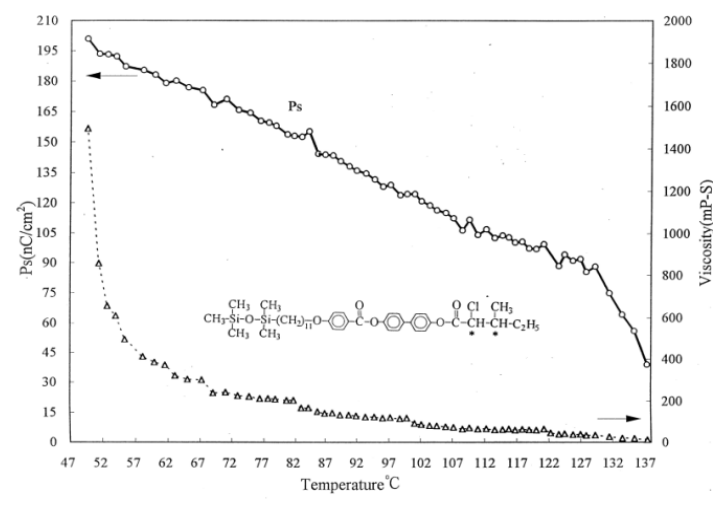

(A)

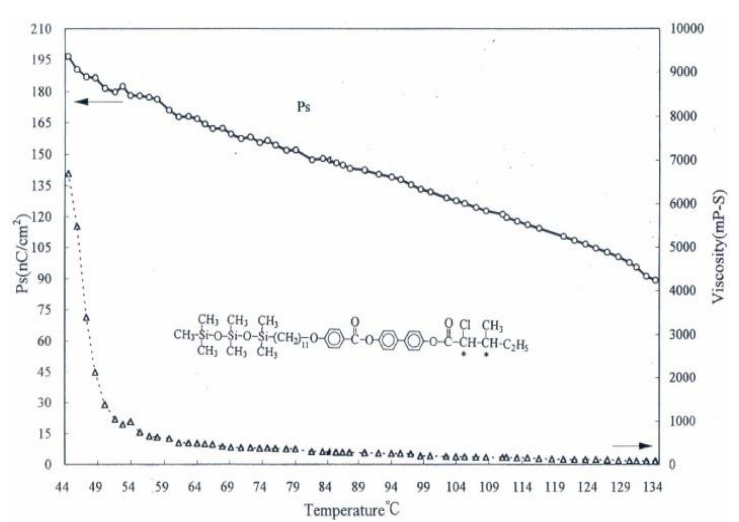

(B)

In comparison of the thermal transitions between these two series of compounds (series UBPV and series UPBV) and pervious synthesized LCs (5M, 5A, and 5B) [17], some results are summarized as follows: (a) Within the same series, the siloxane group inductions made the liquid crystalline temperature range of a liquid crystal compound become wider. As shown in Figure 5, the liquid crystalline temperature range of compound $5 \mathrm{M}$ is $27.0{ }^{\circ} \mathrm{C}$, but the liquid crystalline temperature range of compound $5 \mathrm{~A}$ rises up to $35.2{ }^{\circ} \mathrm{C}$. The liquid crystalline temperature range of compound UBPV is $46.2{ }^{\circ} \mathrm{C}$, but the liquid crystalline temperature range of compound $\mathrm{d}$-Si-UBPV and t-Si-UBPV increases to $110{ }^{\circ} \mathrm{C}$. The liquid crystalline temperature range of compound UPBV is $82.6{ }^{\circ} \mathrm{C}$, but the liquid crystalline temperature range of compound d-Si-UPBV and t-Si-UPBV rises up to $152{ }^{\circ} \mathrm{C}$. Figure 6 shows the phase transition temperature of the nine compounds, measured during the cooling process. There is a trend that the siloxane group inductions also lowered the transition temperature of the liquid crystalline mesophase, as clearly stated in Figure 5. Although the liquid crystalline mesophase of bis-siloxane compound is similar to that of the tris-siloxane compound, the tris-siloxane compound has a lower phase transition temperature than that of the bis-siloxane compound; (b) The three phenyl molecules (series UBPV and series UPBV) formulate a much wider liquid crystalline phase temperature range than the two phenyls molecules $(5 \mathrm{M}, 5 \mathrm{~A}$, and 5B) do. As shown in Figure 5, the liquid crystalline temperature range of $5 \mathrm{M}, 5 \mathrm{~A}$, and $5 \mathrm{~B}$ is about $27.0 \sim 36.8^{\circ} \mathrm{C}$; the liquid crystalline 
temperature range of series UBPV was measured to be about $46.2 \sim 114{ }^{\circ} \mathrm{C}$, and the liquid crystalline temperature range of series UPBV was measured to be about $82.6 \sim 154{ }^{\circ} \mathrm{C}$. At the same time, three phenyl molecules possess much wider temperature ranges of $\mathrm{S}_{\mathrm{C}} *$ phase than the two phenyl molecules do. For example, the $\mathrm{S}_{\mathrm{C}}$ * liquid crystalline phase temperature range of $5 \mathrm{M}, 5 \mathrm{~A}$, and $5 \mathrm{~B}$ is about 15.8 28.3 ${ }^{\circ} \mathrm{C}$, but the liquid crystalline phase temperature range of series UPBV reaches about $100{ }^{\circ} \mathrm{C}$; (c) In the UBPV series and UPBV series, the differences of phenyl ring arrangements for the mesogenic unit result in the greater differences of the liquid crystal phase formation; the $S_{B}$ phase is the main phase for the UBPV series, while the $\mathrm{Sc}^{*}$ phase is the main for the UPBV series. Leadbetter, Forst, and Mazid synthesized 4- $n$-alkoxyphenyl-4'-octyloxybiphenyl-4-carboxylate [21-23] which is equipped with a $S_{B}$ phase. In addition, the UBPV series compounds, in this study, possess the same three phenyls arrangement as that of Leadbetter, Forst, and Mazid. In other words, both studies possess the same $S_{B}$ phase. In addition, the structure of biphenylcarboxylate would produce electronic resonance, which results in the increase of dipoles at the sides of the whole molecule and the gravitation among molecules. The biphenylcarboxylate group here could be seen as a charge transfer (CT) molecule, which shows the displacement of the d-electron cloud. In other words, the biphenylcarboxylate group has an electronic resonance structure (as shown in Figure 7). It can exhibit a large change in dipole moment. Therefore, the increase of dipole induces the molecular interaction, and the standardized arrangement of the $S_{B}$ phase is formed. However, no similar resonance happens in the UPBV series compounds. Therefore, the factor of the differences of resonance may help explain the physical differences of liquid crystalline between the UBPV series compounds and the UPBV series compounds.

Figure 5. Liquid crystal temperature ranges of $5 \mathrm{M}, 5 \mathrm{~A}, 5 \mathrm{~B}{ }^{\mathrm{a}}$, UBPVs, and UPBVs. ${ }^{\mathrm{a}}$ The chemical structure of $5 \mathrm{M}, 5 \mathrm{~A}$, and $5 \mathrm{~B}$ [17].

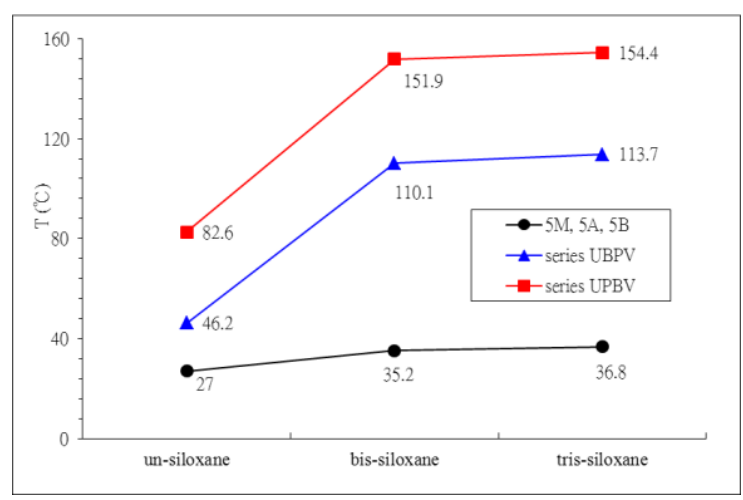

Figure 6. The phase transition temperatures of $5 \mathrm{M}, 5 \mathrm{~A}, 5 \mathrm{~B}$, series UBPV, and series UPBV, which were measured during the cooling process. * chiral center.

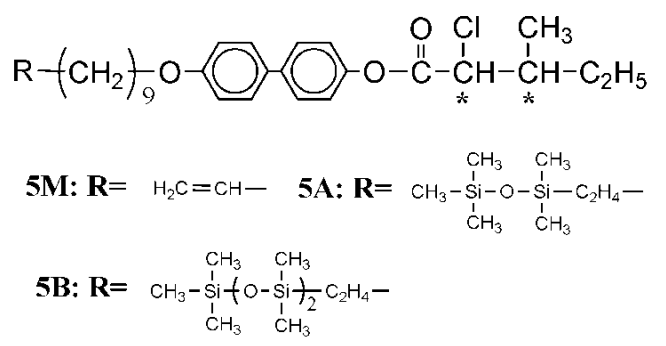


Figure 6. cont.

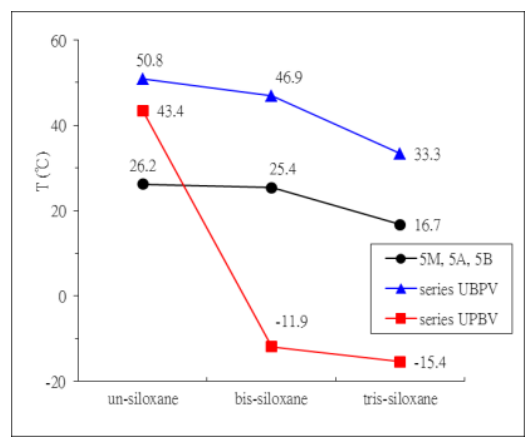

Figure 7. The resonance structure of biphenylcarboxylate group.

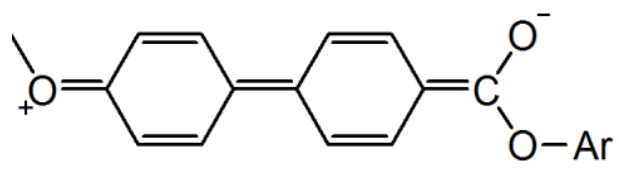

\section{Experimental Section}

${ }^{1} \mathrm{H}-\mathrm{NMR}$ spectra were recorded on a Varian (CA, USA) VXR-300 or Bruker (MA, USA) $300 \mathrm{MHz}$ spectrometer. Thermal transitions and thermodynamic parameters were determined using a Seiko (Tokyo, Japan) SSC/5200 DSC equipped with a liquid nitrogen cooling accessory. Heating and cooling rates were $10{ }^{\circ} \mathrm{C} / \mathrm{min}$. Thermal transition reports were collected during the second heating and cooling scans. A Nikon (Tokyo, Japan) Microphot-FX POM equipped with a Mettler (OH, USA) FP 82 hot stage and a FP 80 central processor was used to observe the thermal transitions and analyze the anisotropic textures. Polymerization reactions were traced using a Nicolet (WI, USA) 520 FT-IR spectrometer.

\subsection{Synthesis}

The general synthetic routes of the intermediates and target molecule are shown in Schemes 1,2. The purity and chemical structures of the intermediates and target compounds can be easily verified by TLC and ${ }^{1} \mathrm{H}-\mathrm{NMR}$ spectroscopy. The synthetic procedures and chemical analyses of each product are described, sequentially, below.

3.1.1. 4-Hydroxyphenyl(2S,3S)-2-chloro-3-methylvalerate (1) and 4-Hydroxybiphenyl-4'-yl(2S,3S)-2chloro-3-methylvalerate (2)

Compounds 1,2 were prepared by the same method. The synthesis of compound $\mathbf{1}$ is described below.

To a solution of hydroquinone $(2.0 \mathrm{~g}, 18.2 \mathrm{mmol})$ and $(2 S, 3 S)$-2-chloro-3-methylvaleric acid (2.6 g, $17.2 \mathrm{mmol})$ in dry dichloromethane $(100 \mathrm{~mL})$, dry THF $(20 \mathrm{~mL}), N, N$-dicyclohexylcarbodiimide (DCC, $3.7 \mathrm{~g}, 17.9 \mathrm{mmol}$ ) and 4-(N,N-dimethyl-amino)-pyridine (DMAP, $0.1 \mathrm{~g}$ ) were added, to react under nitrogen, in a $250 \mathrm{~mL}$ two-neck flask. The reaction mixture was stirred for $24 \mathrm{~h}$ at room temperature. The solution was filtered and washed with an excess of dichloromethane. The filtrate was 
washed with water and dried over anhydrous magnesium sulfate. After removal of the solvent, using evaporation under reduced pressure, the residue was purified by column chromatography on silica gel using hexane/ethyl acetate as eluent to yield $2.42 \mathrm{~g}(58 \%)$ of yellow oil liquid. ${ }^{1} \mathrm{H}-\mathrm{NMR}(300 \mathrm{MHz}$, $\left.\mathrm{CDCl}_{3}, \delta, \mathrm{ppm}\right): 0.78-1.04\left(\mathrm{~m}, 6 \mathrm{H},-\mathrm{C}_{3}\right), 1.20-2.10\left(\mathrm{~m}, 3 \mathrm{H},-\mathrm{C} \underline{\mathrm{H}}-\underline{\mathrm{C}}_{2}-\mathrm{CH}_{3}\right), 4.42(\mathrm{~d}, 1 \mathrm{H}$, $-\mathrm{C}$ HCl-COO-), 6.75 (m, 4H, aromatic protons).

Compound 2 was produced as $2.11 \mathrm{~g}(42 \%)$ of yellow solid. $m p=91.3{ }^{\circ} \mathrm{C} .{ }^{1} \mathrm{H}-\mathrm{NMR}(300 \mathrm{MHz}$, $\left.\mathrm{CDCl}_{3}, \delta, \mathrm{ppm}\right): 0.78-1.04\left(\mathrm{~m}, 6 \mathrm{H},-\mathrm{CH}_{3}\right), 1.20-2.10\left(\mathrm{~m}, 3 \mathrm{H},-\mathrm{C} \underline{\mathrm{H}}-\underline{\mathrm{C}}_{2}-\mathrm{CH}_{3}\right), 4.38(\mathrm{~d}, 1 \mathrm{H}$, $-\mathrm{C} \underline{\mathrm{HCl}}-\mathrm{COO}-$ ), 6.79-7.51 (m, 8H, aromatic protons).

\subsubsection{4-(10-Undecenyloxy)biphenyl-4'-carboxylic acid (3)}

4-(4'-Hydroxyphenyl)benzoic acid (4 g, $18.7 \mathrm{mmol}$ ) was added to a solution of potassium hydroxide $(2.1 \mathrm{~g}, 37.5 \mathrm{mmol})$ in ethanol $(500 \mathrm{~mL}, 95 \%)$. Potassium iodide $(0.2 \mathrm{~g})$ was also added and the solution was heated to reflux for $0.5 \mathrm{~h}$. 10-Undecenyl-1-tosylate $(6.1 \mathrm{~g}, 18.9 \mathrm{mmol})$ was then slowly added and the solution was heated to reflux overnight. The solution was then extracted with $100 \mathrm{~mL}$ of dichloromethane and $50 \mathrm{~mL} 6 \mathrm{~N} \mathrm{HCl}$. The extraction solution was dried over anhydrous magnesium sulfate. After removal of the solvent by evaporation under reduced pressure, the residue was recrystallized from ethanol to yield $2.94 \mathrm{~g}$ (43\%) of white crystal. The remaining white solid $m p=165.5{ }^{\circ} \mathrm{C} .{ }^{1} \mathrm{H}-\mathrm{NMR}\left(300 \mathrm{MHz}, \mathrm{CDCl}_{3}, \delta, \mathrm{ppm}\right): 1.27-2.10\left(\mathrm{~m}, 16 \mathrm{H},-\left(\mathrm{C}_{2}\right)_{8}-\right), 3.96(\mathrm{t}, 2 \mathrm{H}$, $-\mathrm{C}_{2} \mathrm{O}-$ ) $, 5.02\left(\mathrm{~m}, 2 \mathrm{H}, \underline{\mathrm{C}}_{2}=\mathrm{CH}-\right), 5.84\left(\mathrm{~m}, 1 \mathrm{H}, \mathrm{CH}_{2}=\mathrm{C} \underline{\mathrm{H}}-\right), 6.90$ (m, 2H, aromatic protons), 7.53 (m, $4 \mathrm{H}$, aromatic protons), 8.02 ( $\mathrm{m}, 2 \mathrm{H}$, aromatic protons).

\subsubsection{Ethyl-4-(10-undecenyloxy)benzoate (4)}

Ethyl-4-hydroxybenzoate $(2.0 \mathrm{~g}, 0.012 \mathrm{~mol})$, 10-undecenyl-1-tosylate $(3.9 \mathrm{~g}, 0.012 \mathrm{~mol})$, and potassium carbonate $(8.0 \mathrm{~g}, 0.058 \mathrm{~mol})$ were dissolveted in $100 \mathrm{~mL}$ of anhydrous ethylmethylketone in a $250 \mathrm{~mL}$ two-neck flask. The solution was heated to reflux for $48 \mathrm{~h}$. The solution was cooled and filtrated. Following the solvent being evaporated, the residue was purified by column chromatography (silica gel, using $n$-hexane/ethyl acetate as an eluent) to yield $3.24 \mathrm{~g}(85 \%)$ of oil liquid. ${ }^{1} \mathrm{H}-\mathrm{NMR}$ (300 MHz, $\left.\mathrm{CDCl}_{3}, \delta, \mathrm{ppm}\right): 1.27-2.10\left(\mathrm{~m}, 19 \mathrm{H},-\left(\mathrm{C}_{2}\right)_{8}-\right.$ and $\left.-\mathrm{CH}_{2}-\mathrm{C}_{3}\right), 3.96\left(\mathrm{t}, 2 \mathrm{H},-\mathrm{C}_{2} \mathrm{O}-\right), 4.03$ (t, $\left.2 \mathrm{H},-\mathrm{COO}-\mathrm{C}_{2}-\right), 5.02\left(\mathrm{~m}, 2 \mathrm{H}, \mathrm{CH}_{2}=\mathrm{CH}-\right), 5.84\left(\mathrm{~m}, 1 \mathrm{H}, \mathrm{CH}_{2}=\mathrm{C} \underline{\mathrm{H}}-\right)$ ) $6.86(\mathrm{~m}, 2 \mathrm{H}$, aromatic protons), 7.83 ( $\mathrm{m}, 2 \mathrm{H}$, aromatic protons).

\subsubsection{4-(10-Undecenyloxy)benzoic acid (5)}

Ethyl-4-(10-undecenyloxy)benzoate $(1.53 \mathrm{~g}, 4.8 \mathrm{mmol})$ was added to a solution of sodium hydroxide $(1.2 \mathrm{~g}, 0.030 \mathrm{~mol})$ in methanol $(30 \mathrm{~mL}, 90 \%)$. The solution was cooled and poured into $10 \mathrm{~mL}$ of $6 \mathrm{~N} \mathrm{HCl}$, and the solution was then extracted with $30 \mathrm{~mL}$ of dichloromethane. The extraction solution was dried over anhydrous magnesium sulfate. Following removal of the solvent by evaporation under reduced pressure, the residue was purified by recrystallization from ethanol to yield $1.32 \mathrm{~g}(95 \%)$ of white crystal. ${ }^{1} \mathrm{H}-\mathrm{NMR}\left(300 \mathrm{MHz}, \mathrm{CDCl}_{3}, \delta, \mathrm{ppm}\right): 1.26-1.74\left(\mathrm{~m}, 14 \mathrm{H},-\left(\mathrm{C}_{2}\right)_{7}-\right)$, 1.96-2.01 (m, 2H, $\left.-\underline{\mathrm{C}}_{2}-\mathrm{CH}=\right), 3.96\left(\mathrm{t}, 2 \mathrm{H},-\underline{\mathrm{C}}_{2} \mathrm{O}-\right), 5.02\left(\mathrm{~m}, 2 \mathrm{H}, \mathrm{C}_{2}=\mathrm{CH}-\right), 5.84(\mathrm{~m}, 1 \mathrm{H}$, $\left.\mathrm{CH}_{2}=\mathrm{C} \underline{\mathrm{H}}-\right)$, 6.86 (m, $2 \mathrm{H}$, aromatic protons), 7.96 (m, $2 \mathrm{H}$, aromatic protons). 
3.1.5. 4-[4-(10-Undecenyloxy)biphenyl-4'-carbonyloxy]phenyl(2S,3S)-2-chloro-3-methylvalerate (UBPV) and 4-[4-(10-Undecenyloxy)phenyl-4'-carbonyloxy]biphenyl(2S,3S)-2-chloro-3methylvalerate (UPBV)

Compounds UBPV,UPBV were prepared by the same method. The synthesis of compound UPBV is described below.

4-Hydroxybiphenyl-4'-yl(2S,3S)-2-chloro-3-methylvalerate $\quad(2) \quad\left(\begin{array}{llll}1.1 & \mathrm{~g}, & 3.4 & \mathrm{mmol}\end{array}\right)$ and 4-(10-undecenyloxy)benzoic acid (5) (1.0 g, $3.4 \mathrm{mmol})$ dissolved in dry dichloromethane (100 $\mathrm{mL})$, $N, N$-dicyclohexylcarbodiimide (DCC, $0.85 \mathrm{~g}, 4.1 \mathrm{mmol}$ ) and 4-(N,N-dimethyl-amino)-pyridine (DMAP, $0.1 \mathrm{~g}$ ) were added to react under nitrogen. The reaction mixture was stirred for $48 \mathrm{~h}$ at room temperature. The solution was filtered and washed with an excess of dichloromethane. The filtrate was washed with water and dried over anhydrous magnesium sulfate. After removal of the solvent by evaporation under reduced pressure, the residue was purified by column chromatography on silica gel using hexane/ethyl acetate as eluent to yield $1.35 \mathrm{~g}(67 \%)$ of white crystal. $\mathrm{mp}=44.2{ }^{\circ} \mathrm{C}$. ${ }^{1} \mathrm{H}-\mathrm{NMR}$ (300 MHz, $\left.\mathrm{CDCl}_{3}, \delta, \mathrm{ppm}\right): 0.78-2.20\left(\mathrm{~m}, 25 \mathrm{H},-\mathrm{C}_{3},-\left(\mathrm{C}_{2}\right)_{8}-,-\mathrm{C} \underline{\mathrm{H}}-\mathrm{C}_{2}-\mathrm{CH}_{3}\right), 4.02(\mathrm{t}, 2 \mathrm{H}$, $\left.-\underline{\mathrm{C}}_{2} \mathrm{O}-\right), 4.40(\mathrm{~d}, 1 \mathrm{H},-\mathrm{C} \underline{\mathrm{HCl}}), 5.01\left(\mathrm{~m}, 2 \mathrm{H},=\underline{\mathrm{C}}_{2}\right), 5.80\left(\mathrm{~m}, 1 \mathrm{H}, \mathrm{CH}_{2}-\mathrm{C} \underline{\mathrm{H}}=\right), 6.92-8.18(\mathrm{~m}, 12 \mathrm{H}$, aromatic protons).

Compound UBPV was obtained as white solids $(1.17 \mathrm{~g}, 47 \%) . \mathrm{mp}=55.8{ }^{\circ} \mathrm{C} .{ }^{1} \mathrm{H}-\mathrm{NMR}(300 \mathrm{MHz}$, $\mathrm{CDCl}_{3}, \delta$, ppm): 0.78-2.20 (m, 25H, $\left.-\underline{\mathrm{CH}}_{3},-\left(\mathrm{C}_{2}\right)_{8}-,-\underline{\mathrm{CH}}_{-}-\underline{\mathrm{C}}_{2}-\mathrm{CH}_{3}\right), 4.02\left(\mathrm{t}, 2 \mathrm{H},-\underline{\mathrm{CH}}_{2} \mathrm{O}-\right), 4.42(\mathrm{~d}$, $1 \mathrm{H},-\mathrm{C} \underline{\mathrm{HCl}}), 5.01\left(\mathrm{~m}, 2 \mathrm{H},=\underline{\mathrm{C}}_{2}\right), 5.80\left(\mathrm{~m}, 1 \mathrm{H}, \mathrm{CH}_{2}-\mathrm{C} \underline{\mathrm{H}}=\right), 6.98-8.21$ (m, 12H, aromatic protons).

\subsubsection{Liquid Crystal Siloxane Compounds d-Si-UBPV, t-Si-UBPV, d-Si-UPBV, and t-Si-UPBV}

Siloxane dimer synthesized from UBPV and UPBV are marked as d-Si-UBPV and d-Si-UPBV; siloxane trimer from UBPV and UPBV are marked as t-Si-UBPV and t-Si-UPBV. Compounds $\mathrm{d}-\mathrm{Si}$-UBPV, t-Si-UBPV, d-Si-UPBV, and t-Si-UPBV were prepared using the same method. The synthesis of compound t-Si-UPBV is described below.

To a degassed solution of compound UPBV $\left(\begin{array}{lllll}0.5 & \mathrm{~g}, & 0.8 & \mathrm{mmol}) & \text { and }\end{array}\right.$ 1,1,1,3,3,5,5-heptamethyltrisiloxane $(0.21 \mathrm{~g}, 0.9 \mathrm{mmol})$ in $10 \mathrm{~mL}$ of dry, freshly distilled toluene was added divinyltetramethyldimethylsiloxyl $(2.5 \mathrm{mg})$ as catalyst. The reaction mixture was stirred at $70{ }^{\circ} \mathrm{C}$ under nitrogen for $48 \mathrm{~h}$. Following the solvent being evaporated, the residue was purified by column chromatography (silica gel, using $n$-hexane/ethyl acetate as an eluent) to yield $0.30 \mathrm{~g}(69 \%)$ of white crystal. ${ }^{1} \mathrm{H}-\mathrm{NMR}\left(300 \mathrm{MHz}, \mathrm{CDCl}_{3}, \delta, \mathrm{ppm}\right): 0.0\left(\mathrm{~m}, 21 \mathrm{H},-\mathrm{Si}-\mathrm{C}_{3}\right), 0.53(\mathrm{~m}, 2 \mathrm{H}$, $\left.-\mathrm{Si}-\underline{\mathrm{C}}_{2}-\mathrm{CH}_{2}-\right), 0.78-2.20\left(\mathrm{~m}, 27 \mathrm{H},-\underline{\mathrm{C}}_{2}-,-\underline{\mathrm{C}}_{2}-\underline{\mathrm{C}}_{3}\right.$, and $\left.-\mathrm{C} \underline{\mathrm{H}}-\underline{\mathrm{C}}_{3}\right), 4.02$ (t, 2H, $\left.-\mathrm{O}-\underline{\mathrm{C}}_{2}-\right)$, $4.40(\mathrm{~d}, 1 \mathrm{H},-\mathrm{C} \underline{\mathrm{HCl}}-), 6.92-8.18$ (m, 12H, aromatic protons).

\section{Conclusions}

The induction of the soft siloxane molecules is helpful to change the liquid crystalline phase and shift the liquid crystalline temperature. It also broadens the liquid crystal temperature range of $\mathrm{S}_{\mathrm{C}} *$ without inducing chain crystallization phenomenon and diluting the $P s$ value, simultaneously. The siloxane molecule induction is helpful to the smectic phase formation and smectic phase stabilization such as the $\mathrm{S}_{\mathrm{C}} *$ and $\mathrm{S}_{\mathrm{B}}$ phases. The mesogenic units of three phenyl molecules (series UBPV and 
series UPBV) formulate much wider liquid crystalline phase temperature range than two phenyl (5M, $5 \mathrm{~A}$ and 5B) do. The phenyl arrangement differences of mesogenic units result in the greater differences of the liquid crystal phase formation; the $S_{B}$ phase is the head of the UBPV series, while the $\mathrm{S}_{\mathrm{C}}$ * phase is the head of the UPBV series.

\section{Acknowledgments}

Research was supported in part by Chang Gung University of Science and Technology grant EZRPF3C0321, EZRPF3C0331, and EZRPF3C0341.

\section{Conflicts of Interest}

The authors declare no conflict of interest.

\section{References}

1. Corsellis, E.A.; Coles, H.J. Thermal behaviour and electro-optic properties of a nematic exhibiting cyclic siloxane. Mol. Cryst. Liq. Cryst. 1995, 261, 71-78.

2. Newton, J.; Coles, H.J.; Hodge, P.; Hannington, J. Synthesis and properties of low-molar liquid-crystalline siloxane derivatives. J. Mater. Chem. 1994, 4, 869-874.

3. Coles, H.J.; Owen, H.; Newton, J.; Hodge, P. New low molar mass organosiloxanes with unusual ferroelectric properties. Liq. Cryst. 1993, 15, 739-744.

4. Coles, H.J.; Owen, H.; Newton, J., Hodge, P. Electro-optic effects in novel siloxane containing oligomeric liquid crystals II: Smectic C materials. Proc. SPIE 1995, 2408, 22-29.

5. Kloess, P.; McComb, J.; Coles, H.J.; Zentel, R. Synthesis and properties of a new series of low-molar-mass organo-siloxane derivatives. Ferroelectrics 1996, 180, 233-243.

6. Scherowsky, G.; Schliwa, A.; Springer, J.; Kuhnpast, K.; Trapp, W. Fast switching ferroelectric liquid-crystalline polymers. Liq. Cryst. 1989, 5, 1281-1295.

7. Shibaev, V.P.; Kozlovsky, M.V.; Plate, N.A. Ferroelectric liquid-crystalline polymethacrylates. Liq. Cryst. 1990, 8, 545-551.

8. Vallerien, S.U.; Kremer, F.; Fischer, E.W. Experimental proof of piezoelectricity in cholesteric and chiral smectic $C^{*}$-phases of LC-elastomers. Makromol. Chem. Rapid Commun. 1990, 11, 593-598.

9. Kapitza, H.; Zentel, R. Chiral liquid-crystalline polymers by polymer-analogous reactions. Makromol. Chem. 1991, 192, 1859-1872.

10. Endo, H.; Hachiya, S.; Uchida, S.; Hashimoto, K.; Kawasaki, K. Helical pitch of ferroelectric liquid-crystalline polymers and copolymers. Liq. Cryst. 1991, 9, 635-641.

11. Vallerien, S.U.; Kremer, F.; Kapitza, H.; Zentel, R.; Fischer, E.W. Softmode at the ferroelectric/non ferroelectric phase-transition in a liquid crystalline polymer. Ferroelectrics $\mathbf{1 9 9 0}$, 109, 273-278.

12. Lagerwall, S.T.; Dahl, I. Ferroelectric liquid crystals. Mol. Cryst. Liq. Cryst. 1984, 114, 151-187.

13. Lagerwall, S.T.; Otterholm, B.; Skarp, K. Material properties of ferroelectric liquid crystals and their relevance for applications and devices. Mol. Cryst. Liq. Cryst. 1987, 152, 503-587. 
14. Roberts, J.C.; Kapernaum, N.; Giesselmann, F.; Wand, M.D.; Lemieux, R.P. Fast switching organosiloxane ferroelectric liquid crystals. J. Mater. Chem. 2008, 18, 5301-5306.

15. Grüneberg, K.; Naciri, J.; Shashidhar, R. Ferroelectric properties of a fast switching cyclic siloxane oligomer. Chem. Mater. 1996, 8, 2486-2498.

16. Keith, C.; Reddy, R.A.; Baumeister, U.; Tschierske, C. Banana-shaped liquid crystals with two oligosiloxane end-groups: Field-induced switching of supramolecular chirality. J. Am. Chem. Soc. 2004, 126, 14312-14313.

17. Lin, C.H. Synthesis and characterization of ferroelectric liquid crystalline siloxanes containing 4-hydroxyphenyl(2S,3S)-2-chloro-3-methylvalerate. Mol. Cryst. Liq. Cryst. 2012, 552, 33-42.

18. Naciri, J.; Ruth, J.; Grawford, G.; Shashidhar, R.; Ratna, B.R. Novel ferroelectric and electroclinic organosiloxane liquid crystals. Chem. Mater. 1995, 7, 1397-1402.

19. Hsu, C.S.; Her, B.S. Synthesis of ferroelectric liquid-crystalline polymethacrylates containing 1,2-diphenylethane based mesogens. Macromol. Chem. Phys. 1996, 197, 4105-4118.

20. Liao, C.T.; Wu, Z.L.; Wu, N.C.; Liu, J.Y.; Jiang, M.H.; Zou, S.F.; Lee, J.Y. Low-temperature and wide ferroelectric phase in mixtures of chiral and non-chiral tilted smectic C-type liquid crystals. Mol. Cryst. Liq. Cryst. 2010, 533, 3-15.

21. Leadbetter, A.J.; Forst, J.C.; Mazid, M.A. Interlayer correlations in smectic B phases. J. Physique Lett. 1979, 40, 325-329.

22. Goodby, J.W.; Gray, G.W.; McDonnell, D.G. Dipole moments and the smectic C phase. Mol. Cryst. Liq. Cryst. 1976, 34, 183-188.

23. Goodby, J.W.; Gray, G.W. A natural progression from smectic C to tilted smectic B properties in the n-Alkyl 4'-n-Alkoxybiphenyl-4-carboxylates. Mol. Cryst. Liq. Cryst. 1978, 48, 127-149.

(C) 2013 by the authors; licensee MDPI, Basel, Switzerland. This article is an open access article distributed under the terms and conditions of the Creative Commons Attribution license (http://creativecommons.org/licenses/by/3.0/). 